\title{
Ultrasonographic Assessment of the Diaphragm in Chronic Obstructive Pulmonary Disease Patients: Relationships with Pulmonary Function and the Influence of Body Composition - A Pilot Study
}

\author{
Andrea Smargiassi Riccardo Inchingolo Linda Tagliaboschi \\ Alessandro Di Marco Berardino Salvatore Valente Giuseppe Maria Corbo \\ Pulmonary Medicine Department, Università Cattolica del Sacro Cuore, Rome, Italy
}

For editorial comment see p. 355

\section{Key Words}

Chronic obstructive pulmonary disease - Diaphragm - Chest ultrasound

\begin{abstract}
Background: Skeletal muscle weakness with loss of fat-free mass (FFM) is one of the main systemic effects of chronic obstructive pulmonary disease (COPD). The diaphragm is also involved, leading to disadvantageous conditions and poor contractile capacities. Objectives: We measured the thickness of the diaphragm (TD) by ultrasonography to evaluate the relationships between echographic measurements, parameters of respiratory function and body composition data. Methods: Thirty-two patients (23 males) underwent (1) pulmonary function tests, (2) echographic assessment of TD in the zone of apposition at various lung volumes, i.e. TD at residual volume (TDRV), TD at functional residual capacity (TDFRC) and TD at total lung capacity (TDTLC), and (3) bioelectrical body impedance analysis. The BMI and the BODE (BMI-Obstruction-Dyspnea-Exercise) index values were reported. Results: TDRV, TDFRC and TDTLC measured 3.3, 3.6 and $6 \mathrm{~mm}$, respectively, with good intraobserver reproducibility $(0.97,0.97$ and 0.96 , respectively). All the TDs were found to be related to FFM, with the relationship being
\end{abstract}

greater for TDFRC $\left(r^{2}=0.39\right.$ and $\left.p=0.0002\right)$. With regard to lung volumes, inspiratory capacity (IC) was found to be closely related to TDTLC $\left(r^{2}=0.42\right.$ and $\left.p=0.0001\right)$. The difference between TDTLC and TDRV, as a thickening value (TDTLCRV), was closely related to FVC $\left(r^{2}=0.34\right.$ and $p=$ 0.0004 ) and to air-trapping indices (RV/TLC, FRC/TLC and IC/ $T L C)$ : the degree of lung hyperinflation was greater and the TDTLCRV was less. Finally, we found a progressive reduction of both thicknesses and thickenings as the severity of IC/TLC increased, with a significant $p$ value for the trend in both analyses $(p=0.02)$. Conclusions: Ultrasonographic assessment of the diaphragm could be a useful tool for studying disease progression in COPD patients, in terms of lung hyperinflation and the loss of FFM.

(c) 2014 S. Karger AG, Basel

\section{Introduction}

Chronic obstructive pulmonary disease (COPD) is a progressive disease characterized by an incomplete reversible airflow limitation.

This work has been presented as poster at ERS congress 2012, Vienna.

\section{KARGER}

E-Mail karger@karger.com

www.karger.com/res
(C) 2014 S. Karger AG, Basel

0025-7931/14/0875-0364\$39.50/0
Riccardo Inchingolo, MD

Pulmonary Medicine Department

Università Cattolica del Sacro Cuore, Largo Gemelli 8

IT-00168 Roma (Italy)

E-Mail r_inchingolo@virgilio.it 
The disease is determined by the manifestation of chronic inflammation with acute exacerbations, alterations in repair mechanisms, remodeling, oxidative stress imbalance and 'spill-over' of inflammatory mediators into the circulation, resulting in important systemic manifestations [1].

Systemic inflammation can initiate or worsen comorbid diseases such as ischemic heart disease, heart failure, osteoporosis, normocytic anemia, lung cancer, depression and diabetes. These diseases potentiate the morbidity of COPD, leading to increased hospitalization, mortality and healthcare costs, and complicating the management of COPD patients [1].

Systemic inflammation, deconditioning, oxidative stress, nutritional imbalance, cardiac failure, hypoxemia and hypercapnia can also lead to a loss of fat-free mass (FFM) [2] and to weakening of the skeletal muscles, considered to be the main systemic effects influencing the progression of the disease $[3,4]$. Long-term administration of steroids (even low doses), used widely in the treatment of COPD, can also contribute to respiratory muscle weakness with wasting of the diaphragm muscle $[5,6]$.

Several studies have shown that the function and structure of skeletal muscle are altered in COPD patients and these abnormalities are related to respiratory function, exercise intolerance, health status, mortality and the utilization of healthcare resources [7-9]. Muscle wasting is associated with a loss of muscle strength and has therefore been identified as a significant determinant of mortality in COPD, independent of lung function, smoking and BMI [7-9].

It has been demonstrated that FFM is more accurate than BMI for predicting COPD severity, as it is related not only to the distance walked in the 6-minute walk test (6MWT) but also to the $\mathrm{FEV}_{1} / \mathrm{FVC}$ ratio, the Modified Medical Research Council (MMRC) dyspnea scale and the percentage of predicted $\mathrm{FEV}_{1}$ [10].

The diaphragm is the main respiratory muscle. $\mathrm{Pa}$ tients affected by emphysematous COPD with a loss of FFM and muscle wasting show profound alterations regarding the mass, thickness and area of the diaphragm [11-13].

The study of the diaphragm is thus considered a key point in the evaluation of patients with severe COPD and several methods are employed such as magnetic resonance scans [14], phrenic-nerve conduction study [15] and invasive assessment of transdiaphragmatic pressure (the difference between the intrathoracic and intraabdominal pressure during the respiratory cycle) [16].

Role of Diaphragmatic Ultrasonography in COPD
Recently, the use of ultrasonographic (US) techniques for the assessment of both diaphragmatic excursions [17, 18] and thickness of the diaphragm (TD) at different lung volumes [19] has been proposed. The reproducibility of measurements and the relationships between diaphragm kinetics and respiratory functional parameters have been investigated in normal subjects.

TD is also related to muscle mass. Recently, in patients with cystic fibrosis, TD has been found to be related to both lung volume and FFM [20].

In COPD patients, obtaining a noninvasive evaluation of the diaphragmatic function from US measurements of thickness, thickening and excursions could be a useful way to estimate the severity of the disease.

The aim of our study was to investigate, in a sample of COPD patients, the US features of the diaphragm (i.e. thickness, thickening and excursions) in relation to both body composition (in terms of FFM) and pulmonary function.

\section{Materials and Methods}

This protocol received the approval of the Ethical Committee of the Catholic University of the Sacred Heart, Rome (No. P/498/ $\mathrm{CE} / 2011$ ), and every patient gave her/his written informed consent.

\section{Study Design}

The study included COPD patients from April 2011.

The diagnosis of COPD was based on an investigation of their medical history, a clinical examination and respiratory function tests [21].

Patients were included who had an $\mathrm{FEV}_{1} / \mathrm{FVC}$ ratio of $<70 \%$, irreversible after the administration of beta2 agonists (reversibility test). Patients affected by neurological disease, lung cancer, pleural effusion, chemical pleurodesis, interstitial lung disease or with a pacemaker device or a medical history of major surgical chest/abdominal intervention were excluded.

The patients underwent respiratory function tests, echographic measurements and bioelectrical impedance analysis.

\section{Methods}

Pulmonary Function Tests

Each patient underwent pulmonary function tests using the technique of body plethysmography (Platinum Elite Series ${ }^{\mathrm{TM}}$, Medical Graphics Corp., Milan, Italy).

These tests included simple spirometry with the measurement of pulmonary slow and forced flows, lung volumes and airways resistance, reversibility with beta2 agonists and lung diffusion of carbon monoxide (DLCO). Respiratory function tests were performed according to other studies [22-24].

Three reproducible maneuvers were obtained for each test and the best one was reported.

Finally, each patient underwent a 6MWT [25]. The distance walked, the arterial oxygen saturation of hemoglobin (measured by pulse oximeter at the beginning and end of the exercise) and the 
Table 1. Descriptive characteristics of the study population

\begin{tabular}{|c|c|c|c|}
\hline & Mean & $\begin{array}{l}\text { Standard } \\
\text { deviation }\end{array}$ & Median \\
\hline Age, years & 71.8 & 8.32 & 72 \\
\hline $\mathrm{FEV}_{1}$, liters & 1.25 & 0.43 & 1.23 \\
\hline $\mathrm{FEV}_{1}, \%$ & 50.6 & 16.3 & 47 \\
\hline FVC, liters & 2.6 & 0.81 & 2.48 \\
\hline FVC, \% & 81.1 & 20.9 & 78.5 \\
\hline VC, liters & 3.02 & 0.85 & 3.02 \\
\hline $\mathrm{VC}, \%$ & 89.7 & 19.8 & 88 \\
\hline $\mathrm{FEV}_{1} / \mathrm{FVC}$ & 0.48 & 0.1 & 0.48 \\
\hline $\mathrm{DLCO} / \mathrm{VA}$ & 2.92 & 0.97 & 2.86 \\
\hline DLCO/VA, \% & 66.5 & 22.5 & 65 \\
\hline TLC, liters & 6.68 & 1.37 & 6.59 \\
\hline TLC, \% & 112 & 21 & 109 \\
\hline FRC, liters & 4.3 & 1.15 & 4.05 \\
\hline IC, liters & 2.37 & 0.74 & 2.42 \\
\hline $\mathrm{RV}$, liters & 3.69 & 1.17 & 3.41 \\
\hline $\mathrm{RV}, \%$ & 152 & 48.5 & 149 \\
\hline FRC/TLC & 0.64 & 0.08 & 0.62 \\
\hline IC/TLC & 0.36 & 0.08 & 0.38 \\
\hline RV/TLC & 0.54 & 0.1 & 0.57 \\
\hline Distance walked, m & 387.76 & 125.9 & 400 \\
\hline BODE index value & 2.9 & 1.95 & 3 \\
\hline BMI & 27.6 & 5.2 & 27.5 \\
\hline Height, m & 1.67 & 0.01 & 1.68 \\
\hline FFM, kg & 53.3 & 9.2 & 55.5 \\
\hline
\end{tabular}

$\mathrm{VA}=$ Alveolar volume

degree of dyspnea estimated according to the MMRC scale [26] were reported. The collection of these parameters allowed calculation of the BODE (BMI-Obstruction-Dyspnea-Exercise) index score [27] for each patient.

\section{Echographic Measurements}

Echographic measurements were performed using a MyLab ${ }^{\mathrm{TM}}$ 50 Gold Cardiovascular (Esaote Spa, Rome, Italy) ultrasound machine with probes of 3.5-5 and 7.5-12 MHz.

Each patient was asked to lie in a semirecumbent position (i.e. a bed slope of $45^{\circ}$ ).

The excursion of the right hemidiaphragm during maximal profound inspiration starting from normal end-expiratory volume (functional residual capacity, FRC) was obtained by means of a US technique reported by Testa et al. [18].

We performed an examination using a convex probe of $4 \mathrm{MHz}$.

Measurements of TD and diaphragm kinetics at the zone of apposition were performed using a technique similar to that presented by Ueki et al. [19]. TD was measured at the closest point to the 'curtain sign' in which the two hyperecogenic parallel layers of the diaphragm were clearly identified in the right intercostal position.

We performed the examination by means of intercostal scanning, using a linear probe of $10 \mathrm{MHz}$, with the patient lying in a semirecumbent position. The TD measurements were made at the end of a normal expiration (corresponding to FRC), during a breath-holding maneuver after maximal inspiration (corresponding to total lung capacity, TLC) and at the end of maximal expiration (corresponding to residual volume, RV), and they were reported as TDFRC, TDTLC and TDRV, respectively. Two measurements were performed by the same operator (A.S.) blinded to the result, and the mean value was then reported.

The differences between TDTLC and TDFRC (TDTLCFRC) and TDTLC and TDRV (TDTLCRV) were reported as diaphragm thickenings.

Bioelectrical Impedance Analyses

Bioelectrical body impedance assessment was performed by means of a Tanita SC-240 MA impedentiometer (Biologica Tecnologia Médica SL, Barcelona, Spain). Bioelectrical impedance analysis is a method for estimating body composition by introducing the weight, height and waist circumference of each subject from the determined impedance a number of parameters [28-30].

The FFM for each patient was also reported.

\section{Analysis}

Functional parameters, body composition data and echographic parameters were reported as means and standard deviations.

The reproducibility of the echographic measurements was calculated by the reproducibility coefficient of Bland and Altman [31]. The intraclass analysis of correlation, reporting the intraclass $\mathrm{R}$ factor, was performed to define the significance. ANOVA was used for comparison analysis.

The relationships between functional, echographic and body composition variables were analyzed by means of linear and multiple regression models. Firstly, we analyzed the relation between TD and static lung volume (TLC, FRC, IC and RV), their ratios (RV/TLC, IC/TLC and FRC/TLC) and FFM separately. To define the determinant factors of TDTLC, a multiple regression was performed including TDTLC as an independent parameter and lung volume and FFM as dependent variables. Secondly, the relation between diaphragm thickening with dynamic volumes, such as $\mathrm{FVC}$ and $\mathrm{FEV}_{1}$, static volumes, ratios and FFM was evaluated. The same analysis was performed as that for diaphragmatic excursion. Lastly, to define the determinant factors of TDTLCRV, a multiple regression was performed.

In order to better evaluate the effects of air trapping on TD and diaphragm thickening, we divided COPD patients into 3 groups, based on the frequency distribution of the variable IC/TLC, each group corresponding to a tertile of the distribution: score $0=\mathrm{IC} /$ TLC $>0.40$ (group 0 ), score $1=$ IC/TLC between 0.40 and 0.31 (group 1) and score $2=$ IC/TLC $<0.31$ (group 2). The mean values of thicknesses and thickenings were calculated for each group; they were adjusted for FFM and a test for trend was applied.

Statistical significance was considered for $\mathrm{p}<0.05$.

\section{Results}

\section{Descriptive Statistics}

Thirty-two COPD patients (23 males) were enrolled in this study. The mean BMI was $27.6 \pm 5.2$ with a minimum value of 17.2 and a maximum value of 38.8 , ranging from underweight to subjects affected by 2 nd-degree obesity. 
Table 1 shows the descriptive characteristics of the study population.

The respiratory function tests showed patients belonging to every COPD severity grade [32] with high levels of air trapping: mild $(\mathrm{n}=3)$, moderate $(\mathrm{n}=11)$, severe $(\mathrm{n}=$ 14 ) and very severe $(n=4)$. The median BODE index value was 3 with a maximum value of 7 and a minimum value of 0 .

We reported high intraoperator reproducibility for the echographic measurements (table 2).

The measurements were performed twice by the same operator and the mean value was reported for subsequent statistical analysis.

The diaphragmatic excursion and TD are shown in table 3 .

TD changed according to lung volumes increasing slightly, passing from RV to FRC and sharply from FRC to TLC (fig. 1). TD was significantly greater in males than in females $(\mathrm{p}<0.001)$.

\section{TD, FFM and Lung Volume}

$\mathrm{TD}$ at different lung volumes was closely related to IC, vital capacity (VC) and TLC, showing TDTLC to have the closest relationships with IC and VC $\left(\mathrm{r}^{2}=0.42\right.$ and $\mathrm{p}=$ 0.0001 in both cases). Moreover, TDTLC was related to all indices of air trapping: directly to IC/TLC $(\mathrm{p}=0.01)$, inversely to FRC/TLC and to RV/TLC ( $p=0.01$ and $p=$ 0.02 , respectively; table 4 ).

FFM showed significant direct correlations with all TD measurements (i.e. TDFRC, TDTLC and TDRV), with closer relationships with TDFRC and TDTLC $\left(\mathrm{r}^{2}=0.39\right.$ and $\mathrm{p}=0.0002$ and $\mathrm{r}^{2}=0.32$ and $\mathrm{p}=0.0008$, respectively). Lastly, all thicknesses were found to be related to physical characteristics like height and BMI (table 4). The multiple regression analysis demonstrated that the best model $\left(\mathrm{r}^{2}=0.58\right)$ investigating TDTLC included IC $(\mathrm{p}=0.0003)$ and FFM $(p=0.011)$ as determinant factors.

\section{Thickenings and Excursion}

Both TDTLCFRC and TDTLCRV were closely related to VC, FVC and IC. TDTLCRV and TDTLCFRC were related to air-trapping indices (RV/TLC, FRC/TLC and IC/TLC): the degree of lung hyperinflation was greater and that of TDTLCRV and TDTLCFRC was less. Moreover, a close relationship was found between diaphragm thickenings and $\mathrm{FEV}_{1}$ (table 5).

Diaphragm excursion did not show any relationship with the parameters of respiratory function but was found to be closely related to BMI $\left(\mathrm{r}^{2}=0.29\right.$ and $\left.\mathrm{p}=0.001\right)(\mathrm{ta}-$ ble 5).

Role of Diaphragmatic Ultrasonography in COPD

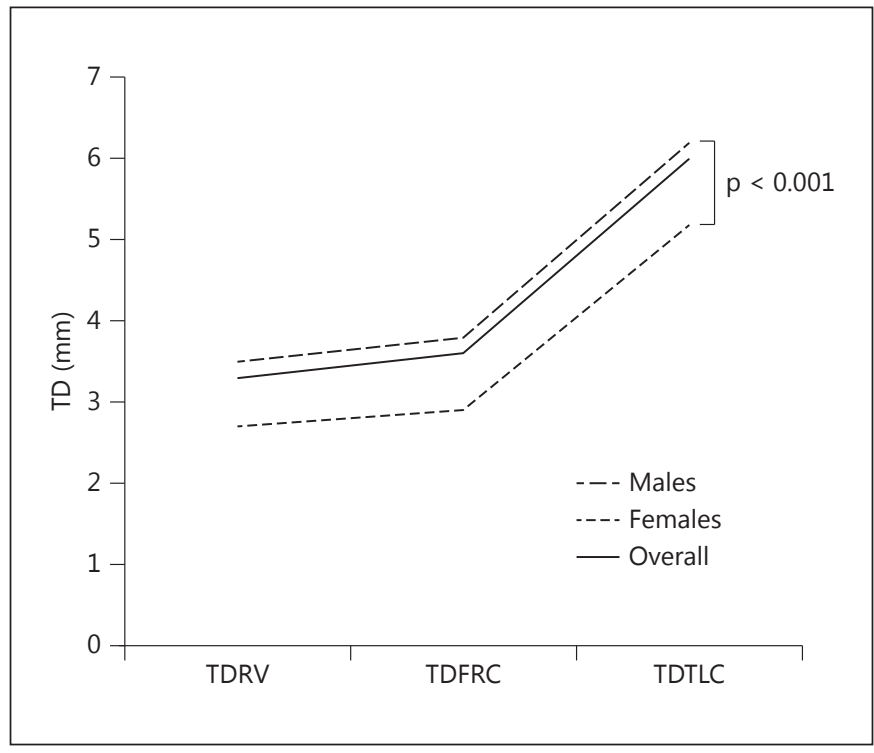

Fig. 1. TD changes according to lung volumes. TDs are significantly greater in males than in females.

Table 2. Intraoperator reproducibility of diaphragm measurements

\begin{tabular}{llllll}
\hline & Mean 1 & Mean 2 & Mean & $\begin{array}{l}\text { Coefficient of } \\
\text { reproducibility }\end{array}$ \\
\hline Excursion & 6.0 & 6.2 & 6.1 & 1.8 & 0.90 \\
TDRV & 3.3 & 3.3 & 3.3 & 0.3 & 0.97 \\
TDFRC & 3.6 & 3.6 & 3.6 & 0.4 & 0.97 \\
TDTLC & 5.9 & 6.1 & 6.0 & 0.7 & 0.96 \\
\hline
\end{tabular}

Table 3. Diaphragm echographic measurements

\begin{tabular}{llll}
\hline & Mean & Standard deviation & Median \\
\hline Excursion, cm & 6.1 & 1.98 & 6.2 \\
TDRV, mm & 3.3 & 0.66 & 3.3 \\
TDFRC, mm & 3.6 & 0.71 & 3.7 \\
TDTLC, mm & 6.0 & 0.96 & 6.1 \\
\hline
\end{tabular}

TDTLCRV and TDTLCFRC did not show any relationship with body composition data.

The multiple regression analysis demonstrated that the best model $\left(\mathrm{r}^{2}=0.58\right)$ investigating TDTLCRV included IC/TLC $(\mathrm{p}=0.0001)$ and $\mathrm{FEV}_{1} / \mathrm{FVC}(\mathrm{p}=0.008)$ as determinant factors. 
Table 4. Correlations between TDs at different lung volumes and lung volumes, ratios, FFM and BMI

\begin{tabular}{|c|c|c|c|c|c|c|c|c|c|}
\hline & \multicolumn{3}{|c|}{ TDFRC } & \multicolumn{3}{|c|}{ TDTLC } & \multicolumn{3}{|c|}{ TDRV } \\
\hline IC, liters & 0.41 & 0.18 & 0.01 & 0.84 & 0.42 & 0.0001 & 0.39 & 0.19 & 0.01 \\
\hline RV, liters & 0.15 & 0.06 & NS & 0.006 & 0.0001 & NS & 0.16 & 0.08 & NS \\
\hline FRC, liters & 0.20 & 0.10 & 0.06 & 0.06 & 0.005 & NS & 0.17 & 0.09 & 0.09 \\
\hline FRC/TLC & -0.98 & 0.01 & NS & -4.72 & 0.18 & 0.01 & -0.99 & 0.01 & NS \\
\hline IC/TLC & 0.98 & 0.01 & NS & 4.72 & 0.18 & 0.01 & 0.99 & 0.01 & NS \\
\hline FFM, kg & 0.05 & 0.39 & 0.0002 & 0.06 & 0.32 & 0.0008 & 0.04 & 0.30 & 0.0012 \\
\hline BODE index value & -0.03 & 0.01 & NS & -0.07 & 0.02 & NS & -0.03 & 0.008 & NS \\
\hline BMI & 0.06 & 0.21 & 0.0078 & 0.07 & 0.16 & 0.021 & 0.06 & 0.24 & 0.0039 \\
\hline
\end{tabular}

Table 5. Relationships between diaphragm thickenings and excursion with lung volumes, ratios, FFM and BMI

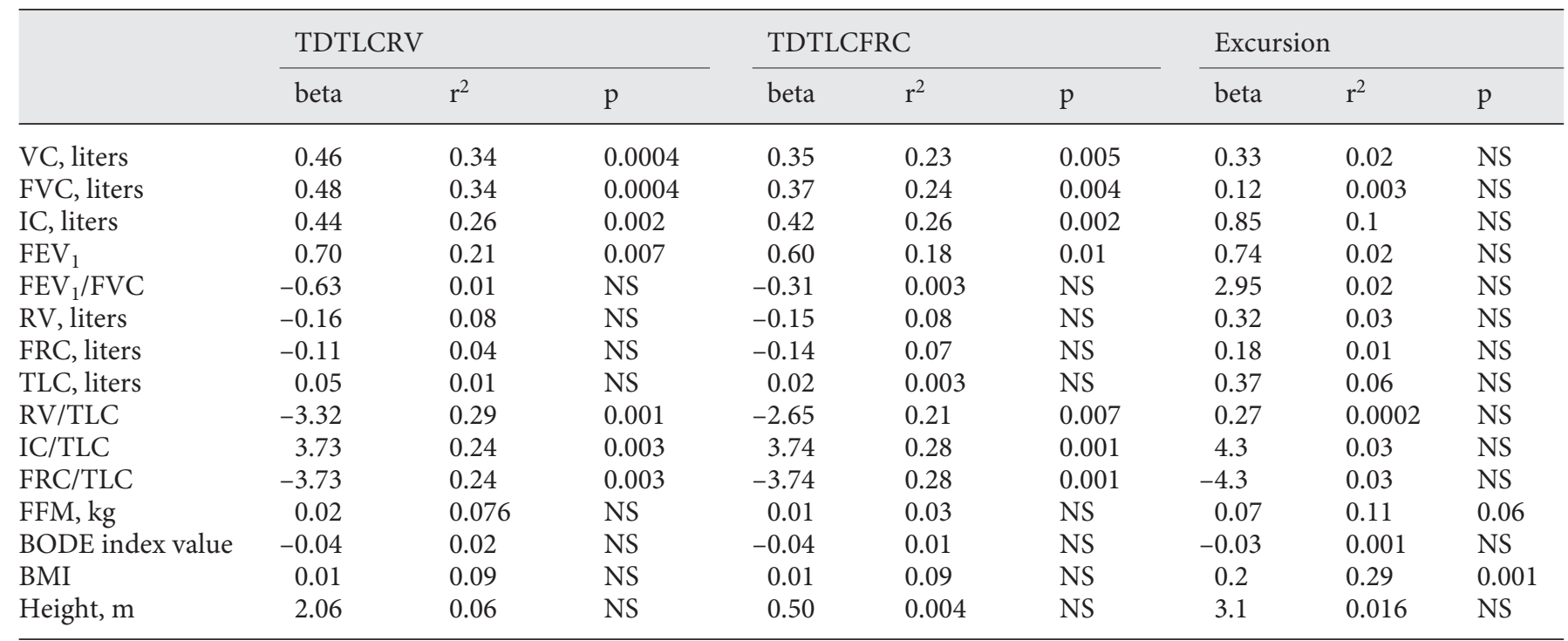

Role of IC/TLC Values on Thickness and Thickening

Figure 2 shows the TDTLC and TDTLCRV mean values adjusted for FFM for each group. There was a progressive reduction in both thickness and thickening, increasing the severity of air trapping with a significant $p$ for the trend in both analyses $(\mathrm{p}=0.02)$.

Finally, in our sample, IC/TLC was found to be strongly related to the BODE index value $\left(\mathrm{r}^{2}=0.44\right.$ and $\mathrm{p}=$ $0.0003)$ and the distance walked in the $6 \mathrm{MWT}\left(\mathrm{r}^{2}=0.30\right.$ and $\mathrm{p}=0.002$ ).

\section{Discussion}

Our results demonstrate that TD measured with the US technique in COPD patients was related to lung volume. Moreover, both FFM and BMI were found to have a close association. Indices of lung hyperinflation were found to be related only with regard to the measurement of TDTLC. Diaphragm thickening was related to the indices of lung hyperinflation and dynamic volumes such as $\mathrm{VC}, \mathrm{FVC}$ and $\mathrm{FEV}_{1}$. 
Fig. 2. TDTLC and TDTLCRV mean values adjusted for FFM for each group. There is a progressive reduction of both thicknesses and thickenings, increasing the severity of air trapping.

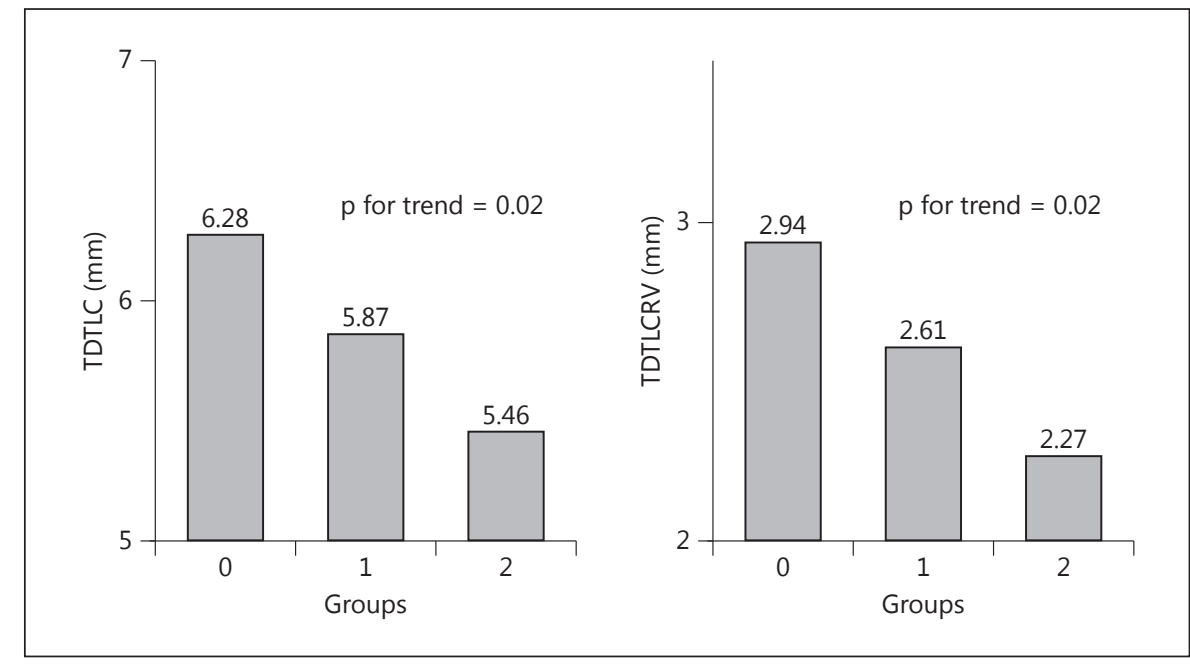

In recent years, the use of ultrasound has gained wide acceptance, also in pneumological settings. However, the US characteristics of respiratory muscles in COPD patients, particularly the diaphragm, have not been fully studied.

Using standard techniques $[18,19]$, the measurement is feasible (perhaps with the exception of severe obesity due to the high acoustic impedance and the thickness of subcutaneous tissues) and reproducible. In our study, we calculated the intraoperator reproducibility and reported a very high level of agreement of both TDs and diaphragm kinetics (table 2), which confirmed previous data on healthy subjects $[17,18,33]$.

According to Cohn et al. [33], we showed that the diaphragm thickened as the lung volume increased, from RV to TLC, with a more rapid rate of thickening at the highest lung volume and a significantly greater thickening in males than in females.

Diaphragm contraction is maximal at full inspiration, so the TDTLC could be considered as an indicator of the contractile capacities of this muscle. These contractile capacities could be limited by both lung hyperinflation and muscle wasting under both these conditions in COPD patients. We found that TDTLC was related to the indices of lung hyperinflation, FFM and BMI. In the multiple regression analysis, the IC and FFM were found to be the main determinants of TDTLC. On the other hand, when the diaphragm relaxed (at FRC), FFM was found to be the main determinant of the TD and there was no association with the indices of lung hyperinflation.

With regard to diaphragmatic thickenings, both TDTLCRV and TDTLCFRC were found to be related to air trapping, hyperinflation indices and dynamic pulmonary volumes (VC, FVC and $\mathrm{FEV}_{1}$ ). No correlation with FFM and BMI was found. Thus, in the dynamic process of thickening, the main role seemed to be played by airflow limitation resulting in air trapping and lung hyperinflation: $\mathrm{FEV}_{1} / \mathrm{FVC}$ and IC/TLC were found to be determinants of TDTLCRV.

Previous papers have stated that IC/TLC is a crucial functional parameter that is related to the BODE index value and the distance walked in the $6 \mathrm{MWT}$ as well as being a predictor of mortality $[34,35]$. As expected, in our sample, IC/TLC was found to be strongly related to the BODE index value and the distance walked in the 6MWT.

The important role of IC/TLC on TD and thickening at TLC (TDTLC and TDTLCRV) can be demonstrated by considering the 3 groups previously described. When TDTLC and TDTLCRV mean values for each group were adjusted for FFM, a significant trend was found: patients with a higher degree of air trapping had a lower TD and thickening at TLC volume (TDTLC and TDTLCRV).

Diaphragmatic excursion must be considered separately. According to some of the authors $[18,36]$ of studies on healthy subjects, no significant relationships were found between the right hemidiaphragmatic excursion and the respiratory function parameters. Others found significant correlations with the degree of air trapping, TLC and $\mathrm{FEV}_{1} / \mathrm{FVC}$ ratio [37], although a different technique was used to establish the excursion. We found that diaphragmatic excursion showed direct significant correlations only with BMI.

Some limitations of the study should be mentioned. Lung flow and volume were measured with the patients 
in an orthostatic position and the echographic measurements were performed holding the patients in a semirecumbent position, according to a technique described by Testa et al. [18]. In this setting, the role played by the abdomen and the abdominal muscles can differ, leading to a reduction of the total inspired volume due to increased air trapping and to a change in the end expiratory volume. Correlations of diaphragm measurements and lung volumes could be affected by this bias. However, we decided to use this technique because we wanted to test the relationships of measurements performed under different conditions, i.e. even in patients who cannot maintain the orthostatic position. The echographic technique of acquisition of TD was therefore quite different from the technique already described by Ueki et al. [19]. We first measured the TD in COPD patients at the closest point to the 'curtain sign' both at FRC and at TLC. Moreover, the patients in our sample were not seated but were in a semirecumbent position. These conditions may modify the echographic characteristics of the diaphragm in the zone of apposition and the behavior of the diaphragm during contraction, especially in hyperinflated COPD subjects.

Another limitation is the mean low-severity score (BODE index) of our sample, with a mortality rate that was significantly greater for a BODE index value of $>6$. Therefore, at the present time, we cannot consider TDs and diaphragm thickenings as prognostic parameters of mortality.

Finally, in our study, only the intraobserver reproducibility was studied, with a high level of agreement. However, in ultrasonography, interobserver agreement is an important issue and this pilot study had the intention of stimulating further studies in order to assess the interobserver reproducibility of TDs in COPD patients.

In conclusion, we suggest that echographic measurements of TDTLC and thickening at TLC might be a useful tool to estimate lung hyperinflation, especially when adjusted for FFM. Moreover, this technique could be feasible in patients in critical clinical settings or those on mechanical ventilation, and facilitate the acquisition of data on diaphragm performance.

\section{References}

1 Barnes PJ, Celli BR: Systemic manifestation and comorbidities of COPD. Eur Respir J 2009;33:1165-1185.

$>2$ Decramer M, De Benedetto F, Del Ponte A, Marinari S: Systemic effects of COPD. Respir Med 2005;99(suppl B):S3-S10.

$\checkmark 3$ Agusti A, Soriano JB: COPD as a systemic disease. COPD 2008;5:133-138.

$\checkmark 4$ Kim HC, Mofarrahi M, Hussain SN: Skeletal muscle dysfunction in patients with chronic obstructive pulmonary disease. Int J Chron Obstruct Pulmon Dis 2008;3:637-658.

$>5$ Decramer M, Lacquet LM, Fagard R, Rogiers $\mathrm{P}$ : Corticosteroids contribute to muscle weakness in chronic airflow obstruction. Am J Respir Crit Care Med 1994;150:11-16.

6 Koerts-de Lang E, Schols AM, Rooyackers OE, Gayan-Ramirez G, Decramer M, Wouters EF: Different effects of corticosteroid-induced muscle wasting compared with undernutrition on rat diaphragm energy metabolism. Eur J Appl Physiol 2000;82:493-498.

$\checkmark 7$ Montes de Oca M, Torres SH, Gonzalez Y, et al: Peripheral muscle composition and health status in patients with COPD. Respir Med 2006;100:1800-1806.

$>8$ Marquis K, Debigare R, Lacasse $\mathrm{Y}$, et al: Midthigh muscle cross-sectional area is a better predictor of mortality than body mass index in patients with chronic obstructive pulmonary disease. Am J Respir Crit Care Med 2002;166:809-813.
-9 Sabino PG, Silva BM, Brunetto AF: Nutritional status is related to fat-free mass, exercise capacity and inspiratory strength in severe chronic obstructive pulmonary disease patients. Clinics 2010;65:599-605.

10 Ischaki E, Papatheodorou G, Gaki E, et al: Body mass and fat-free mass indices in COPD: relation with variables expressing disease severity. Chest 2007;132:164-169.

11 Thurlbeck WM: Diaphragm and body weight in emphysema. Thorax 1978;33:483-487.

$\checkmark 12$ Arora NS, Rochester DF: Effect of body weight and muscularity on human diaphragm muscle mass, thickness, and area. J Appl Physiol 1982;52:64-70.

13 Rochester D: The diaphragm: contractile properties and fatigue. J Clin Invest 1985;75: 1397-1402.

14 Iwasawa T, Takahashi H, Ogura T, et al: Influence of the distribution of emphysema on diaphragmatic motion in patients with chronic obstructive pulmonary disease. Jpn J Radiol 2011;29:256-264.

15 Podnar S, Harlander M: Phrenic nerve conduction studies in patients with chronic obstructive pulmonary disease. Muscle Nerve 2013;47:504-509.

16 Lopez-Navas K, Brandt S, Strutz M, et al: Comparison of two methods to assess transdiaphragmatic pressure at different levels of work of breathing. Biomed Tech 2012, DOI: 10.1515/bmt-2012-4124.
17 Boussuges A, Gole Y, Blanc P: Diaphragmatic motion studied by M-mode ultrasonography: methods, reproducibility, and normal values. Chest 2009;135:391-400.

-18 Testa A, Soldati G, Giannuzzi R, et al: Ultrasound M-mode assessment of diaphragmatic kinetics by anterior transverse scanning in healthy subjects. Ultrasound Med Biol 2011; 37:44-52.

19 Ueki J, De Bruin PF, Pride NB: In vivo assessment of diaphragm contraction by ultrasound in normal subjects. Thorax 1995;50:11571161.

20 Enright S, Chatham K, Ionescu AA, et al: The influence of body composition on respiratory muscle, lung function and diaphragm thickness in adults with cystic fibrosis. J Cyst Fibros 2007;6:384-390.

21 ATS/ERS Task Force: Standards for the diagnosis and treatment of patients with COPD: a summary of the ATS/ERS position paper. Eur Respir J 2004;23:932-946.

-22 ATS/ERS Task Force: Standardisation of spirometry. Eur Respir J 2005;26:319-338.

23 ATS/ERS Task Force: Standardisation of the measurement of lung volumes. Eur Respir J 2005;26:511-522.

24 ATS/ERS Task Force: Standardisation of the single-breath determination of carbon monoxide uptake in the lung. Eur Respir J 2005;26: 720-735. 
25 ATS Committee on Proficiency Standards for Clinical Pulmonary Function Laboratories: ATS statement: guidelines for the six-minute walk test. Am J Respir Crit Care Med 2002; 166:111-117.

26 Mahler D, Wells C: Evaluation of clinical methods for rating dyspnea. Chest 1988;93: 580-586.

27 Celli BR, Cote CG, Marin JM: The body-mass index, airflow obstruction, dyspnea, and exercise capacity index in chronic obstructive pulmonary disease. N Engl J Med 2004;350: 1005-1012.

28 Kyle UG, Bosaeus I, De Lorenzo AD, et al: Bioelectrical impedance analysis. Part I: review of principles and methods. Clin Nutr 2004;23:1226-1243.

29 Kyle UG, Bosaeus I, De Lorenzo AD, et al: Bioelectrical impedance analysis. Part II: utilization in clinical practice. Clin Nutr 2004;23: 1430-1453.
30 Walter-Kroker A, Kroker A, MattiucciGuehlke M, et al: A practical guide to bioelectrical impedance analysis using the example of chronic obstructive pulmonary disease. Nutr J 2011;10:35.

31 Bland JM, Altman DG: Statistical methods for assessing agreement between two methods of clinical measurement. Lancet 1986;1:307-310.

32 Vestbo J, Hurd SS, Agustí AG, Jones PW, Vogelmeier C, Anzueto A, Barnes PJ, Fabbri LM, Martinez FJ, Nishimura M, Stockley RA, Sin DD, Rodriguez-Roisin R: Global strategy for the diagnosis, management, and prevention of chronic obstructive pulmonary disease: GOLD executive summary. Am J Respir Crit Care Med 2013;187:347-365.

33 Cohn D, Benditt JO, Eveloff S, et al: Diaphragm thickening during inspiration. J Appl Physiol 1997;83:291-296.
34 Casanova C, Cote C, de Torres JP, et al: Inspiratory-to-total lung capacity ratio predicts mortality in patients with chronic obstructive pulmonary disease. Am J Respir Crit Care Med 2005;171:591-597.

35 Pinto-Plata VM, Cote C, Cabral H, et al: The 6-min walk distance: change over time and value as a predictor of survival in severe COPD. Eur Respir J 2004;23:28-33.

36 Scott S, Fuld JP, Carter R, et al: Diaphragm ultrasonography as an alternative to wholebody plethysmography in pulmonary function testing. J Ultrasound Med 2006;25:225232

37 Dos Santos Yamaguti WP, Paulin E, Shibao S: Air trapping: The major factor limiting diaphragm mobility in chronic obstructive pulmonary disease patients. Respirology 2008; 13:138-144. 